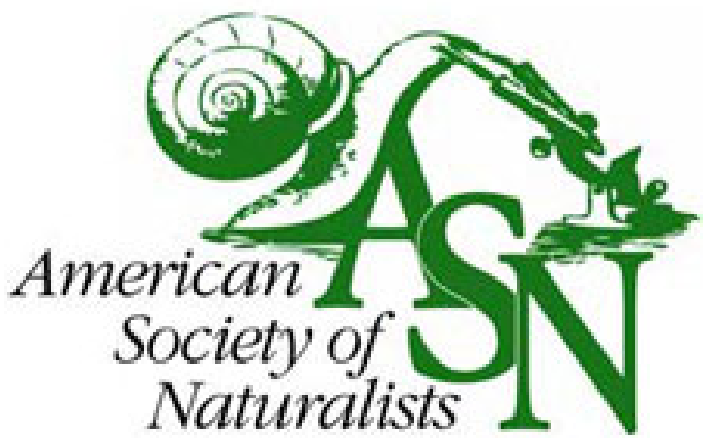

Between-Year Variation in Population Sex Ratio Increases with Complexity of the Breeding System in Hymenoptera.

Author(s): Rolf Kümmerli and Laurent Keller

Source: The American Naturalist, Vol. 177, No. 6 (June 2011), pp. 835-846

Published by: The University of Chicago Press for The American Society of Naturalists

Stable URL: http://www.jstor.org/stable/10.1086/659951

Accessed: 23/05/2011 10:18

Your use of the JSTOR archive indicates your acceptance of JSTOR's Terms and Conditions of Use, available at http://www.jstor.org/page/info/about/policies/terms.jsp. JSTOR's Terms and Conditions of Use provides, in part, that unless you have obtained prior permission, you may not download an entire issue of a journal or multiple copies of articles, and you may use content in the JSTOR archive only for your personal, non-commercial use.

Please contact the publisher regarding any further use of this work. Publisher contact information may be obtained at http://www.jstor.org/action/showPublisher?publisherCode=ucpress.

Each copy of any part of a JSTOR transmission must contain the same copyright notice that appears on the screen or printed page of such transmission.

JSTOR is a not-for-profit service that helps scholars, researchers, and students discover, use, and build upon a wide range of content in a trusted digital archive. We use information technology and tools to increase productivity and facilitate new forms of scholarship. For more information about JSTOR, please contact support@jstor.org.

The University of Chicago Press and The American Society of Naturalists are collaborating with JSTOR to digitize, preserve and extend access to The American Naturalist. 


\title{
Between-Year Variation in Population Sex Ratio Increases with Complexity of the Breeding System in Hymenoptera
}

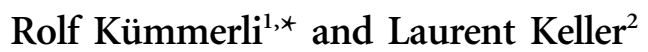 \\ 1. Department of Environmental Microbiology, Swiss Federal Institute of Aquatic Science and Technology (Eawag), Überlandstrasse 133, \\ 8600 Dübendorf, Switzerland; and Department of Environmental Sciences, Swiss Federal Institute of Technology (ETH) Zurich, \\ Universitätstrasse 16, CH-8092 Zurich, Switzerland; 2. Department of Ecology and Evolution, University of Lausanne, Biophore, \\ CH-1015 Lausanne, Switzerland
}

Submitted October 15, 2010; Accepted February 15, 2011; Electronically published April 22, 2011

Dryad data: http://dx.doi.org/10.5061/dryad.8590.

ABSTRACT: While adaptive adjustment of sex ratio in the function of colony kin structure and food availability commonly occurs in social Hymenoptera, long-term studies have revealed substantial unexplained between-year variation in sex ratio at the population level. In order to identify factors that contribute to increased between-year variation in population sex ratio, we conducted a comparative analysis across 47 Hymenoptera species differing in their breeding system. We found that between-year variation in population sex ratio steadily increased as one moved from solitary species, to primitively eusocial species, to single-queen eusocial species, to multiple-queen eusocial species. Specifically, between-year variation in population sex ratio was low (6.6\% of total possible variation) in solitary species, which is consistent with the view that in solitary species, sex ratio can vary only in response to fluctuations in ecological factors such as food availability. In contrast, we found significantly higher (19.5\%) between-year variation in population sex ratio in multiple-queen eusocial species, which supports the view that in these species, sex ratio can also fluctuate in response to temporal changes in social factors such as queen number and queen-worker control over sex ratio, as well as factors influencing caste determination. The simultaneous adjustment of sex ratio in response to temporal fluctuations in ecological and social factors seems to preclude the existence of a single sex ratio optimum. The absence of such an optimum may reflect an additional cost associated with the evolution of complex breeding systems in Hymenoptera societies.

Keywords: social insects, sex allocation, food availability, colony kin structure, worker control versus queen control, nonadaptive pattern.

The ratio of investment should be biased towards females, and in ants it is expected to equilibrate at 3:1 (female to male). (R. L. Trivers and H. Hare 1976)

* Corresponding author; e-mail: rolf.kuemmerli@eawag.ch.

Am. Nat. 2011. Vol. 177, pp. 835-846. (c) 2011 by The University of Chicago. 0003-0147/2011/17706-52549\$15.00. All rights reserved. DOI: $10.1086 / 659951$
No theory of sex-ratio selection can account adequately for systems with tremendously variable sex allocations such as in social insects. (J. M. Herbers 1979)

\section{Introduction}

Since Trivers and Hare (1976) combined Fisher's (1930) sex allocation with Hamilton's (1964) kin-selection theory, patterns of sex allocation in social Hymenoptera (bees, wasps, ants) are interpreted as adaptations that maximize an individual's inclusive fitness (Bourke and Franks 1995; Crozier and Pamilo 1996; Queller and Strassmann 1998; Chapuisat and Keller 1999; Bourke 2005; Meunier et al. 2008; Kümmerli and Keller 2009; West 2009). Trivers and Hare (1976) predicted a conflict between queens and workers over optimal sex allocation, which arises because of the haplodiploid sex determination mechanism (females and males develop from fertilized and unfertilized eggs, respectively; Crozier 1971). This mode of sex determination results in a relatedness asymmetry, whereby workers transmit more of their genes through sisters (relatedness coefficient $r=0.75)$ than through brothers $(r=0.25)$, whereas queens are equally related to their daughters and sons $(r=0.5)$. Consequently, in colonies with one singly mated queen, workers would maximize their inclusive fitness by favoring a $3: 1$ female-biased sex allocation, while queens are best served by a $1: 1$ sex allocation (Trivers and Hare 1976). The worker-queen conflict persists when there is within-population variation in the number of queens per colony and/or the number of mates per queen (i.e., when there is between-colony variation in relatedness asymmetry). Theory predicts here that under worker control, colony sex allocation should be split (Boomsma and Grafen 1990, 1991; Boomsma 1993), with colonies having a relatedness asymmetry above the population average (i.e., those with one singly mated queen) specializing in gyne (virgin queen) production and colonies with a below- 
Table 1: Relationship between Hymenoptera breeding systems and fluctuating factors that can have positive $(+)$ or no $(-)$ effect on between-year variation in population sex ratio

\begin{tabular}{l}
\hline \\
\cline { 2 - 4 }
\end{tabular}

average relatedness asymmetry (i.e., those with multiple queens or those with multiply mated queens) specializing in male production. Overall, the outcome of the workerqueen conflict is determined by the relative power of queens and workers to manipulate sex allocation (Reuter and Keller 2001; Beekman and Ratnieks 2003; Mehdiabadi et al. 2003; Helanterä and Ratnieks 2009; Kümmerli and Keller 2009).

In addition to social factors, numerous studies have shown that colony sex allocation also depends on ecological factors such as food availability (Nonacs 1986; Deslippe and Savolainen 1995; Rosenheim et al. 1996; Herbers and Banschbach 1998, 1999; Morales and Heithaus 1998; Aron et al. 2001; Ode and Rissing 2002; Bono and Herbers 2003; Brown and Keller 2006). Although strong evidence for adaptive sex allocation adjustment in response to social and ecological factors has accumulated over the years (Nonacs 1986; Bourke and Franks 1995; Crozier and Pamilo 1996; Rosenheim et al. 1996; Queller and Strassmann 1998; Chapuisat and Keller 1999; Bourke 2005; Meunier et al. 2008; Helanterä and Ratnieks 2009; Kümmerli and Keller 2009; West 2009), the data also reveal substantial between-year variation in population sex allocation that remains unexplained (Herbers 1979). The extreme temporal fluctuations in population sex allocation observed in some species prompted some researchers to suggest that it can follow nonadaptive patterns (Herbers 1979; Buschinger and Heinze 2001; Liautard et al. 2003).

Here, we investigate why population sex ratio varies dramatically across years in some Hymenoptera species, whereas in others it does not. We do this by conducting a comparative analysis of between-year variation in population sex ratio across 47 species differing in their breeding system. Because data on sex ratio (numerical invest- ment) but not sex allocation (weight investment) were available for most solitary species, we compared betweenyear variation in population sex ratio across species in all our analyses.

Apart from stochastic effects, we can think of at least four potential factors contributing to between-year variation in population sex ratio. We hypothesize that these factors can jointly influence sex ratio decisions, with the number of factors potentially playing a role dependent on the breeding system of a species (table 1). First, betweenyear fluctuation in food availability could lead to temporal variation in population sex ratio because food availability influences the relative fitness returns from male and female offspring (Hymenoptera females are usually larger and more costly to produce than males; Rosenheim et al. 1996). This factor is relevant for all species regardless of their breeding system. Second, between-year variation in worker control versus queen control over sex ratio could explain temporal variation in population sex ratio. This factor is relevant for social species with nonreproducing workers. Third, the process of caste determination (the development of female larvae into queens or workers) is affected by food availability (Aron et al. 2001; Smith 2007), food quality (Bono and Herbers 2003), and temperature (Aron et al. 1994). Between-year fluctuations in these factors may determine the number of diploid eggs, which can develop as queens, or, alternatively, they may influence colony decisions over current versus future reproductive investment strategies (Sundström 1995; Smith 2007). These factors can impact sex ratio in species with morphologically differentiated queens and workers. Fourth, between-year variation in colony queen numbers could alter the number of female- and male-producing colonies in a population and thereby contribute to between-year variation in pop- 
ulation sex ratio. This factor is relevant for species with a variable number of reproducing queens per colony.

Previous studies showed that the experimental manipulation of three of these four factors indeed affected sex ratio by as much as $30 \%-36 \%$ of the maximal possible variation (table 1). Although natural fluctuations in these factors are presumably weaker than those imposed in the experiments, these studies indicate that they can have significant impacts on between-year variation of population sex ratio.

\section{Material and Methods}

\section{Estimating Between-Year Variation in Population Sex Ratio}

We searched the Web of Science (Thomson Reuters) for studies with the keywords "sex allocation" or "sex ratio" and one of the terms "ant(s)," "bee(s)," or "wasp(s)." This resulted in 1,481 hits containing 49 studies that report between-year variation in population sex ratio for 81 populations and 47 species (26 ants, 10 bees, and 11 wasps; note that "wasp" is not a taxonomic term) belonging to 31 genera and 12 families (table 2). From these studies, we extracted data on population sex ratio and/or sex allocation for each study year, measured as the numerical proportion of females or the proportion of weight investment into females, respectively (table 2 ). For the ant species Myrmica tahoensis (Evans 1996) and Pheidole desertorum (Helms 1999), the proportion of femaleproducing colonies had to be used as a measure of population sex ratio. Because colony sex ratio is strongly split in these species, the proportion of female-producing colonies is a good estimate of population sex ratio (e.g., see Helms 1999). Because there were only data on sex ratio (and not sex allocation) for most solitary species (table 2 ), we used (whenever possible) between-year variation in population sex ratio as our response variable in statistical analyses.

For each population, we calculated the standard error (SE) in population sex ratio across years and standardized this estimate across studies by calculating the observed standard error $\left(\mathrm{SE}_{\mathrm{obs}}\right)$ in relation to the maximal possible standard error $\left(\mathrm{SE}_{\max }\right)$, given as $\mathrm{SE}_{\mathrm{obs}} / \mathrm{SE}_{\text {max }}$. This variable is independent of the number of study years and was used as a response variable in our statistical models. Note that $\mathrm{SE}_{\max }$ is straightforward to calculate, as sex ratio varies between 0 and 1 (e.g., for a 2-year study, $\mathrm{SE}_{\max }=0.5$, which is obtained when none and all resources are allocated to females in two consecutive years). Whenever data from multiple populations of the same species were available, we calculated the mean $\mathrm{SE}_{\mathrm{obs}} / \mathrm{SE}_{\max }$ across populations to obtain an average estimate of between-year var- iation in population sex ratio per species (fig. 1). Some (mostly tropical) species produce several brood cohorts a year. For those species, we calculated the average sex ratio per year, including only periods for which data were available for all study years.

\section{Explanatory Variables}

To test whether between-year variation in population sex ratio varies as a function of the breeding system, we classified species as solitary (parasitoids and species with a single independently breeding female), primitively eusocial (a breeding female assisted by one or several totipotent nonbreeding females), single-queen eusocial (a single queen per colony assisted by a morphologically distinct worker caste), or multiple-queen eusocial (multiple queens in all or some colonies within the population, assisted by a morphologically distinct worker caste). Note that in our data set, the first two categories of breeding systems entail only wasp and bee species, whereas the latter two categories consist entirely of ant species. Because for some species (Halictus rubicundus, Formica truncorum, Formica exsecta, Myrmica punctiventris) different populations clearly belong to different categories of breeding systems, they appear twice in table 2 and figure 1 and were treated as independent replicates. Despite having only one queen per colony, we classified the ant species Temnothorax nylanderi as multiple-queen eusocial because colony fusion and queen usurpation are frequent in this species, such that many colonies are genetically heterogeneous, consisting of workers from different matrilines (Foitzik and Heinze 2000). We assigned the breeding systems the values $1-4$ in increasing order of complexity to test for an overall association between breeding system complexity and the between-year variation in sex ratio.

For ants, we further tested whether between-year variation in population sex ratio correlates with the mating structure in a given population/species (fig. 1). Specifically, we classified populations as monoandrous (all queens are singly mated) or polyandrous (some or all queens are multiply mated). Between-year variation in the number of matings per queen could alter the number of female- and male-producing colonies in a population (Boomsma 1993; Sundström et al. 1996) and could therefore induce temporal variation in population sex ratio. Consequently, we would expect variation in population sex ratio to be higher in polyandrous species than in monoandrous species.

We conducted two analyses to check for systematic biases in our data set. Specifically, we tested whether between-year variation in population sex ratio correlates with sample size (i.e., the number of nests used to assess sex ratio) or geographical latitude of populations. Both factors might confound differences in temporal sex ratio 


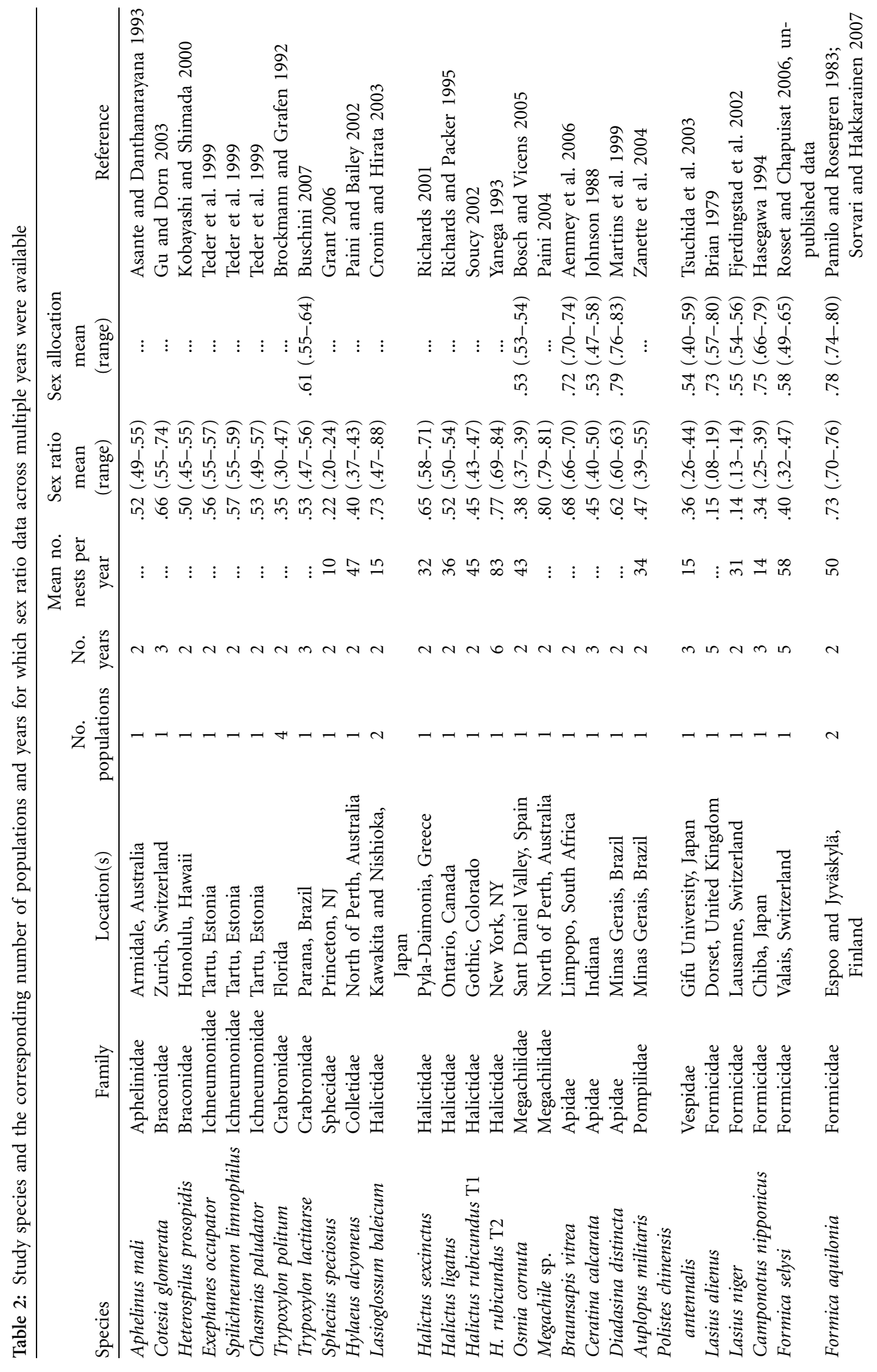




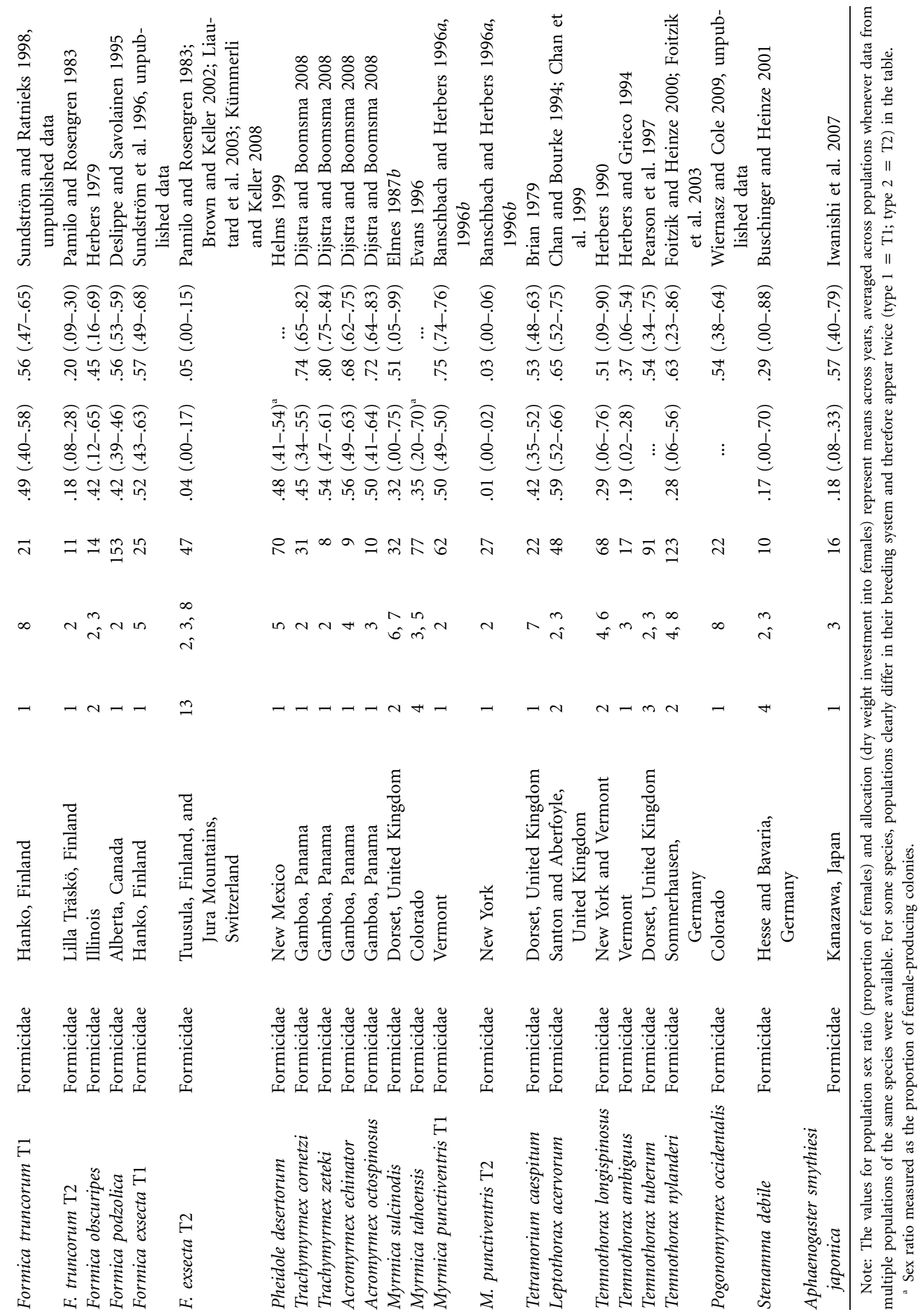




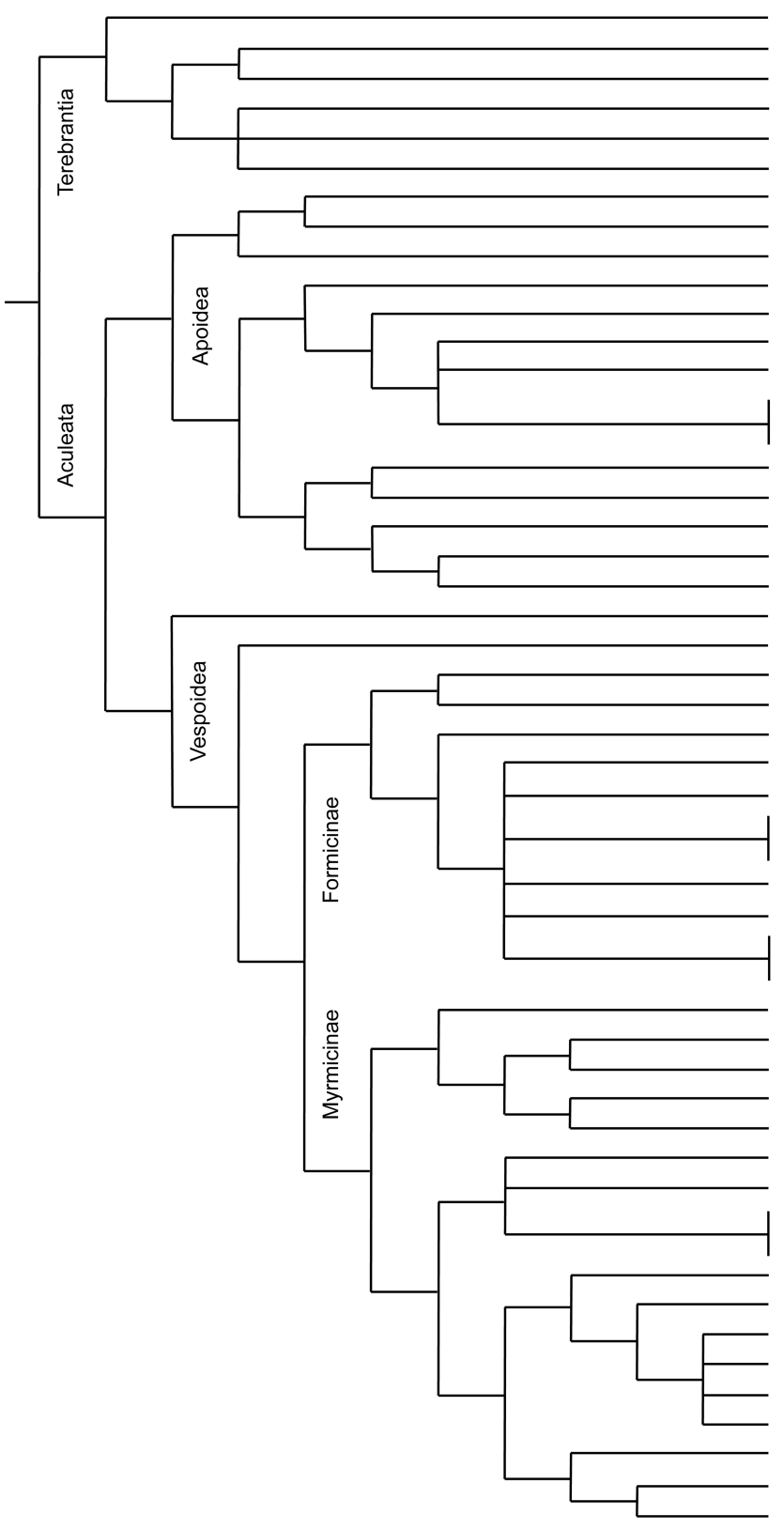

Aphelinus mali

Cotesia glomerata

Heterospilus prosopidis

Exephanes occupator

Spilichneumon limnophilus

Chasmias paludator

Trypoxylon politum

Trypoxylon lactitarse

Specius speciosus

Hylaeus alcyoneus

Lasioglossum baleicum

Halictus sexcinctus

Halictus ligatus

Halictus rubicundus $T 1$

Halictus rubicundus $T 2$

Osmia cornuta

Megachile sp.

Braunsapis vitrea

Ceratina calcarata

Diadasina distinct

Auplopus militaris

Polistes chinensis anten.

Lasius alienus

Lasius niger

Camponotus nipponicus

Formica selysi

Formica aquilonia

Formica truncorum $T 1$

Formica truncorum $T 2$

Formica obscuripes

Formica podzolica

Formica exsecta $T 1$

Formica exsecta $T 2$

Pheidole desertorum

Trachymyrmex cornetzi

Trachymyrmex zeteki

Acromyrmex echinator

Acromyrmex octospinosus

Myrmica sulcinodis

Myrmica tahoensis

Myrmica punctiventris $T 1$

Myrmica punctiventris T2

Tetramorium caespitum

Leptothorax acervorum

Temnothorax longispinosus

Temnothorax ambiguus

Temnothorax tuberum

Temnothorax nylander

Pogonomyrmex occidentalis

Stenamma debile

Aphaenogaster smythiesi jap.

Figure 1: Phylogeny of the study species, including data on between-year variation in population sex ratio, breeding system, and mating structure (for ants only). Because for some species populations clearly differ in their breeding system, they appear twice (type $1=\mathrm{T} 1$; type $2=\mathrm{T} 2$ ) in the figure. For breeding systems, symbols depict solitary (open circles), primitively eusocial (shaded circles), single-queen eusocial (filled circles), or multiple-queen eusocial (doughnuts) species. For mating structure, symbols depict species with monoandrous (open squares) and polyandrous (filled squares) mating systems. Between-year variation in population sex ratio is expressed as the observed standard error divided by the maximal possible standard error across years. 


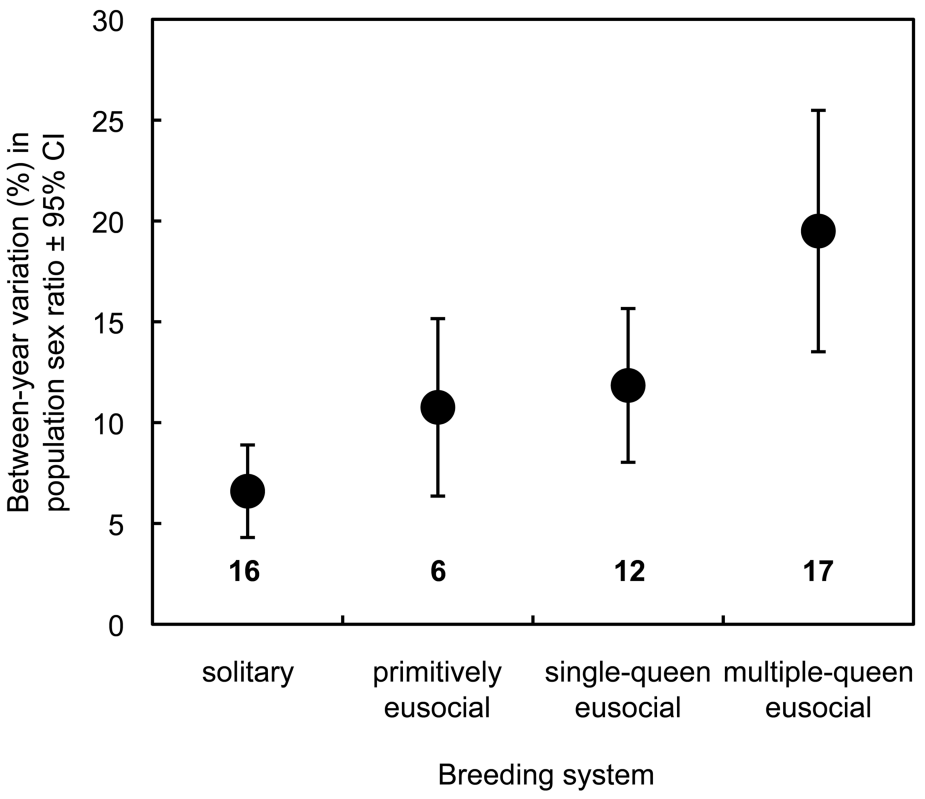

Figure 2: Highly significant positive relationship between the complexity of the breeding system and the between-year variation in population sex ratio. Species were classified as solitary (parasitoids and species with a single independently breeding female per nest), primitively eusocial (a breeding female assisted by one or several totipotent nonbreeding females), single-queen eusocial (a single queen per colony assisted by a morphologically distinct worker caste), or multiple-queen eusocial (multiple queens in all or some colonies within the population, assisted by a morphologically distinct worker caste). The number of species in each category is indicated below the error bars.

variation between breeding systems because certain breeding systems might consistently be associated with low/high sample size or certain ecological conditions (i.e., climate zones). However, we found no evidence for such biases. Although the number of nests sampled varied greatly across species (mean $=40$, range $=8-153$; table 2 ), there was no significant correlation between temporal variation in population sex ratio and nest number (Pearson's product moment correlation: $r=-0.136, \mathrm{df}=37, P=.42$ ). Similarly, although populations were sampled across a wide range of geographical latitude (range $=9.1^{\circ}-61.3^{\circ}$ ), there was no significant correlation between temporal variation in population sex ratio and geographical latitude $(r=-0.090, \mathrm{df}=50, P=.53)$.

\section{Statistical Analysis}

We used a phylogeny-controlled generalized linear mixed model (glmm) to test for associations between breeding system, mating structure, and the between-year variation in population sex ratio. We used the $\mathrm{R}$ package MCMCglmm developed by Hadfield (2010), which is based on a Markov chain Monte Carlo (MCMC) algorithm. This powerful procedure allows analyzing nonGaussian data (our response variable is bounded, varying between 0 and 1) and at the same time controls for phy- logeny by implementing phylogenetic trees as random factors (Hadfield and Nakagawa 2010). For that purpose, we constructed a composite tree with standardized branch lengths between nodes (fig. 1), based on molecular phylogenies of ants (Moreau et al. 2006), bees (Danforth 2006), and the composite trees published by Hughes et al. (2008) and Asplen et al. (2009). We then implemented this phylogeny as a random factor into our models by weighting the relationship between each pair of species by their shared branch length. Although this tree represents the phylogenetic relationships among species as previously inferred, the relative branch lengths are unknown, which might introduce some error. However, this uncertainty is unlikely to affect the outcome of our analysis, because the variance explained by phylogeny $(16.4 \%)$ in our main analysis is relatively small and the impact of erroneous weighting within phylogeny is expected to be even smaller.

To specify appropriate prior distributions required for MCMC procedures, we followed the guidelines of Hadfield (2010) and the MCMCglmm package course notes (http://cran.r-project.org/web/packages/MCMCglmm). For the residual variance structure, we chose an inverseWishart distribution (variance at the limit set to $\mathrm{V}=1$ and the belief parameter $\mathrm{nu}=0.002$ ). For the random factor, we chose a parameter expanded prior to improve mixing and decrease autocorrelation among iterations, 
Table 3: Summary of the statistical analysis testing for a relationship between the between-year variation in population sex ratio and the breeding system in Hymenoptera, as well as the breeding system and the mating structure in ants

\begin{tabular}{|c|c|c|c|c|}
\hline Data set & Dependent variable & Independent variable & $\begin{array}{l}\text { 95\% HPD interval } \\
\text { [lower limit, } \\
\text { upper limit] }\end{array}$ & $\begin{array}{l}\text { 99\% HPD interval } \\
\text { [lower limit, } \\
\text { upper limit] }\end{array}$ \\
\hline All species & Between-year variation in population sex ratio & Breeding system & {$[1.61,6.70]^{\mathrm{a}}$} & {$[.63,7.56]^{\mathrm{a}}$} \\
\hline Ants & Between-year variation in population sex ratio & Breeding system & {$[1.17,14.12]^{\mathrm{a}}$} & {$[-.16,14.85]^{\mathrm{b}}$} \\
\hline Ants & Between-year variation in population sex ratio & Mating structure & {$[-5.94,12.82]^{\mathrm{b}}$} & {$[-10.07,14.85]^{\mathrm{b}}$} \\
\hline
\end{tabular}

with a half-Cauchy distribution described by the parameters $\mathrm{V}=1$, $\mathrm{nu}=1$, the prior mean alpha.mu $=0$, and alpha. $\mathrm{V}=10^{\wedge} 2$, which represents the prior standard deviation with a scale of 10 (Gelman 2006; Hadfield 2010). Both parameter sets result in flat priors, meeting the requirement of not making any a priori predictions on the variance distribution. To test the robustness of our analysis, we used different priors by varying nu $(0.0005<$ nu $<$ $0.05)$ and alpha.V $(25<$ alpha.V $<2,500)$. We found that the outcome of our analysis was not influenced by the choice of priors, underlining the robustness of our tests. All models were run for 170,000 iterations with a burnin phase of 20,000 iterations and a thinning interval of 50.

Note that the MCMC procedure does not provide probability $(P)$ values based on standard distributions (e.g., $t$ distribution) because MCMC generates distributions based on the data, for which probability functions are unknown. Instead, highest posterior density (HPD) intervals can be calculated for each factor level and covariate on the basis of the generated posterior MCMC distributions. Accordingly, we considered differences between factor levels and associations as significant or highly significant when the 95\% HPD or the 99\% HPD intervals did not include 0 (i.e., the value of the null hypothesis of no significant association or no significant difference between factor levels). All statistical analyses were performed in $\mathrm{R}$ 2.10.1 (http://www.r-project.org).

\section{Results}

There was a highly significant positive relationship between the complexity of the breeding system and the between-year variation in population sex ratio (fig. 2; table 3). Phylogenetic relationships explained $16.4 \%$ of the total variance in this analysis.

Regarding ants, between-year variation in population sex ratio was significantly higher for species with multiple queens (mean $\pm \mathrm{SE}=19.5 \% \pm 3.1 \%$ ) than for species with a single queen $(11.8 \% \pm 1.9 \%)$ per colony (table 3$)$.
In contrast, between-year variation in population sex ratio was not significantly different between species with monoandrous $(14.9 \% \pm 2.1 \%)$ and polyandrous $(15.5 \pm 4.3 \%)$ mating structures (table 3 ).

\section{Discussion}

We found strong support for our hypothesis that betweenyear variation in population sex ratio is higher in Hymenoptera species with more complex breeding systems. This suggests that temporal variation in food availability, worker-queen control, factors influencing caste determination, and colony queen number can jointly influence between-year variation in population sex ratio. Hence, on one end of the social spectrum we find solitary species showing relatively little between-year variation in population sex ratio because their sex ratio decisions are affected by temporal variation in ecological factors such as food availability but not temporal variation in social factors. In contrast, on the other end of the social spectrum we find the multiple-queen eusocial species, which show relatively pronounced between-year variation in population sex ratio because their sex ratio decisions can be affected by temporal variation in multiple social factors in addition to ecological factors. In some of these species, the simultaneous plastic adjustment of sex ratio in response to multiple fluctuating factors seems to prevent the emergence of a single stable population sex ratio optimum.

A key question is whether between-year variation in the four proposed factors is indeed responsible for the shifts in population sex ratio reported in our comparative analysis. Support for this comes from experimental studies that induced high shifts in sex ratio following manipulation of one of the factors in question (table 1). For instance, Kümmerli et al. (2005) removed 15.5 (median) queens from 30 colonies across 2 years, which induced between-year variation in sex ratio of $49 \%$, of which $30 \%$ was directly attributable to queen removal. Although such drastic changes in queen number are unlikely to take place from one year to the next under nonmanipulated conditions, 
significant changes in queen number have been observed (Elmes 1987a; Herbers 1990; Herbers and Grieco 1994; Chan et al. 1999; Buschinger and Heinze 2001; Brown and Keller 2002; Kümmerli and Keller 2008), with these being likely to contribute to natural between-year variation in population sex ratio.

There are factors other than those mentioned above that may also contribute to increased between-year variation in population sex ratio. First, reproductive skew among cobreeding queens occurs in many multiple-queen ant species (Ross 1988; Rüppell et al. 2002; Hannonen and Sundström 2003; Fournier et al. 2004; Hammond et al. 2006; Kümmerli and Keller 2007a, 2007b; Yamauchi et al. 2007). Between-year variation in reproductive skew could alter colony kin structure and thus sex ratio decisions (Bourke 2001). Second, one characteristic of multiplequeen ant populations is that nest sites are generally limited such that new queens are often recruited back to their natal colony, with new colonies being formed by budding dispersal (i.e., a fraction of the workers and queens depart from the mother colony to establish a new colony in the vicinity; Keller 1993; Bourke and Franks 1995; Crozier and Pamilo 1996). This mode of dispersal induces local resource competition among related queens and male-biased sex ratios (Frank 1987; Brown and Keller 2000). Consequently, between-year variation in nest site availability may alter queen dispersal behavior and colony founding modes, which would induce changes in colony kin structure and sex ratio decisions. This type of fluctuation might especially be relevant for facultatively polygynous ant species, a type of plastic social organization frequently occurring in habitats characterized by varying degrees of nest-site limitation (Pedersen and Boomsma 1999). Finally, genetic factors influencing caste determination might also impact sex ratio. For example, in some species of Pogonomyrmex ants, the ability to produce workers or queens is dependent on whether the queen has mated with males from the same lineage or an alternate genetic lineage (Helms Cahan and Keller 2003; Schwander et al. 2007). Variation in lineage frequency at the population level has been shown to impact sex ratio (Anderson et al. 2009) and might contribute to between-year variation in population sex ratio in these species.

While we found a significant association between queen number and the between-year variation in population sex ratio in ants, there was no significant association betweer mating structure (i.e., the average number of matings per queen in a population) and between-year variation in population sex ratio. This is despite the fact that both factorsqueen number and mating structure - could influence the between-year variation in population sex ratio equally, as fluctuations would change the proportion of gyne- and male-producing colonies in populations exhibiting spli sex ratios (Boomsma and Grafen 1990, 1991). Our findings therefore suggest that between-year variation in queen number is more common than between-year variation in mating structure. One reason for this might be that the mating status of queen(s) within a colony remains stable, as queens can live many years (Keller and Genoud 1997) and cannot remate later in life. By contrast, queen number per colony is a more plastic trait, as new queens can readily be recruited or evicted between years (Kümmerli and Keller 2008).

In conclusion, this study revealed greater between-year variation in population sex ratio in species with more complex breeding systems (i.e., as one moves along a gradient from solitary species to multiple-queen eusocial species) and identified a number of ecological and social factors that may jointly contribute to such temporal sex ratio variation. The plastic adjustment of sex ratio to multiple factors can lead, in some cases, to putatively nonadaptive sex ratio patterns in multiple-queen ants, as indicated by populations producing only males in certain years (table 2, Formica exsecta T2, Myrmica sulcinodis, Stenamma debile, Myrmica punctiventris T2). Such extreme sex ratios are very surprising, given that males live only a few weeks and queens can mate only within a few days after they eclose from the pupae. This implies that in some years there are no mating opportunities and all males therefore have zero reproductive success. The great between-year variation in sex ratio thus appears to be one additional cost associated with the evolution of complex breeding structures in Hymenoptera.

\section{Acknowledgments}

We thank M. Chapuisat, B. J. Cole, C. Haag-Liautard, L. Sundström, and D. Wiernasz for providing unpublished data; J. Hadfield for support with the statistical analysis; and two anonymous reviewers for their helpful comments. This work was funded by a Marie Curie reintegration grant to R.K. and several grants from the Swiss National Science Foundation.

\section{Literature Cited}

Aenmey, T. K., S. M. Tierney, N. Pillay, and M. P. Schwarz. 2006. Nesting biology of an African allodapine bee Braunsapis vitrea: female biased sex allocation in the absence of worker-like behavioural castes. Ethology Ecology and Evolution 18:205-220.

Anderson, K. E., C. R. Smith, T. A. Linksvayer, B. M. Mott, J. Gadau, and J. H. Fewell. 2009. Modelling the maintenance of a dependent lineage system: the influence of positive frequency-dependent selection on sex ratio. Evolution 63:2142-2152.

Aron, S., L. Passera, and L. Keller. 1994. Queen-worker conflict over 


\section{The American Naturalist}

sex ratio: a comparison of primary and secondary sex ratios in the Argentine ant, Iridomyrmex humilis. Journal of Evolutionary Biology 7:403-418.

$\rightarrow$ Aron, S., L. Keller, and L. Passera. 2001. Role of resource availability on sex, caste and reproductive allocation ratio in the Argentine ant Linepthema humile. Journal of Animal Ecology 70:831-839.

$\rightarrow$ Asante, S. K., and W. Danthanarayana. 1993. Sex ratios in natural populations of Aphelinus mali (Hym: Aphelinidae) in relation to host size and host density. Entomophaga 38:391-403.

$\rightarrow$ Asplen, M. K., J. B. Withfield, J. G. de Boer, and G. E. Heimpel. 2009. Ancestral state reconstruction analysis of hymenopteran sex determination mechanisms. Journal of Evolutionary Biology 22 1762-1769.

$\rightarrow$ Banschbach, V. S., and J. M. Herbers. 1996a. Complex colony struc ture in social insects. I. Ecological determinants and genetic consequences. Evolution 50:285-297.

$\rightarrow \longrightarrow$. 1996b. Complex colony structure in social insects. II. Reproduction, queen-worker conflict, and levels of selection. Evo lution 50:285-297.

$\rightarrow$ Beekman, M., and F. L. W. Ratnieks. 2003. Power over reproduction in social Hymenoptera. Philosophical Transactions of the Royal Society B: Biological Sciences 358:1741-1753.

$\rightarrow$ Bono, J. M., and J. M. Herbers. 2003. Proximate and ultimate control of sex ratios in Myrmica brevispinosa colonies. Proceedings of the Royal Society B: Biological Sciences 270:811-817.

Boomsma, J. J. 1993. Sex ratio variation in polygynous ants. Pages 86-109 in L. Keller, ed. Queen number and sociality in insects Oxford University Press, Oxford.

$\rightarrow$ Boomsma, J. J., and A. Grafen. 1990. Intraspecific variation in ant sex ratios and the Trivers-Hare hypothesis. Evolution 44:10261034.

$\rightarrow$ - 1991. Colony-level sex ratio selection in the eusocial Hymenoptera. Journal of Evolutionary Biology 4:383-407.

$\rightarrow$ Bosch, J., and N. Vicens. 2005. Sex allocation in the solitary bet $\rightarrow$ Osmia cornuta: do females behave in agreement with Fisher's theory? Behavioral Ecology and Sociobiology 59:124-132.

$\rightarrow$ Bourke, A. F. G. 2001. Reproductive skew and split sex ratios in socia $\rightarrow$ Hymenoptera. Evolution 55:2131-2136.

- 2005. Genetics, relatedness and social behavior in insect societies. Pages 1-30 in M. D. E. Fellowes, G. J. Holloway, and J. Rolff, eds. Insect evolutionary ecology. CABI, Cambridge, MA.

Bourke, A. F. G., and N. R. Franks. 1995. Social evolution in ants. Princeton University Press, Princeton, NJ.

$\rightarrow$ Brian, M. V. 1979. Habitat differences in sexual production by twc $\rightarrow$ co-existent ants. Journal of Animal Ecology 48:943-953.

$\rightarrow$ Brockmann, H. J., and A. Grafen. 1992. Sex ratios and life-history patterns of a solitary wasp, Trypoxylon (Trypargilum) politum (Hy menoptera: Sphecidae). Behavioral Ecology and Sociobiology 30: $7-27$.

$\rightarrow$ Brown, W. D., and L. Keller. 2000. Colony sex ratios vary with queer $\rightarrow$ number but not relatedness asymmetry in the ant Formica exsecta. Proceedings of the Royal Society B: Biological Sciences 267:17511757.

$\rightarrow-$ 2002. Queen recruitment and split sex ratios in polygynous colonies of the wood ant Formica exsecta. Ecology Letters 5:102109.

$\rightarrow-$ 2006. Resource supplements cause a change in colony sexratio specialization in the mound-building ant, Formica exsecta $\rightarrow$ Behavioral Ecology and Sociobiology 60:612-618.

$\rightarrow$ Buschinger, A., and J. Heinze. 2001. Stenamma debile (Hymenoptera, $\rightarrow$ Grant, P. R. 2006. Opportunistic predation and offspring sex ratios
Formicidae): productivity and sex allocation across three years. Insectes Sociaux 48:110-117.

Buschini, M. L. T. 2007. Life-history and sex allocation in Trypoxylon (syn. Trypargilum) lactitarse (Hymenoptera; Crabronidae). Journal of Zoological Systematics and Evolutionary Research 45:206-213.

Chan, G. L., and A. F. G. Bourke. 1994. Split sex ratios in a multiplequeen ant population. Proceedings of the Royal Society B: Biological Sciences 258:261-266.

Chan, G. L., A. Hingle, and A. F. G. Bourke. 1999. Sex allocation in a facultatively polygynous ant: between-population and betweencolony variation. Behavioral Ecology 10:409-421.

Chapuisat, M., and L. Keller. 1999. Testing kin selection with sex allocation data in eusocial Hymenoptera. Heredity 82:473-478.

Cronin, A. L., and M. Hirata. 2003. Social polymorphism in the sweat bee Lasioglossum (Evylaeus) baleicum (Cockerell) (Hymenoptera, Halictidae) in Hokkaido, northern Japan. Insectes Sociaux 50:379-386.

Crozier, R. 1971. Heterozygosity and sex determination in haplodiploidy. American Naturalist 105:399-412.

Crozier, R., and P. Pamilo. 1996. Evolution of social insect colonies: sex allocation and kin selection. Oxford University Press, Oxford.

$\rightarrow$ Danforth, B. N. 2006. The history of early bee diversification based on five genes plus morphology. Proceedings of the National Academy of Sciences of the USA 103:15118-15123.

$\rightarrow$ Deslippe, R. J., and R. Savolainen. 1995. Sex investment in a social insect: the proximate role of food. Ecology 76:375-382.

Dijkstra, M. B., and J. J. Boomsma. 2008. Sex allocation in fungusgrowing ants: worker or queen control without symbiont-induced female bias. Oikos 117:1892-1906.

Elmes, G. W. 1987a. Temporal variation in colony populations of the ant Myrmica sulcinodis. I. Changes in queen number, worker number and spring production. Journal of Animal Ecology 56: 559-571.

. 1987b. Temporal variation in colony populations of the ant Myrmica sulcinodis. II. Sexual production and sex ratios. Journal of Animal Ecology 56:573-583.

Evans, J. D. 1996. Temporal and spatial variation in reproduction in the facultatively polygynous ant Myrmica tahoensis (Hymenoptera: Formicidae). Insectes Sociaux 43:309-317.

Fisher, R. A. 1930. The genetical theory of natural selection. Pages 121-145 in J. H. Bennett, ed. The genetical theory of natural selection: a complete variorum edition. Oxford University Press, Oxford.

Fjerdingstad, E. J., P. J. Gertsch, and L. Keller. 2002. Why do some social insect queens mate with several males? testing the sex ratio manipulation hypothesis in Lasius niger. Evolution 56:553-562.

Foitzik, S., and J. Heinze. 2000. Intraspecific parasitism and split sex ratios in a monogynous and monandrous ant (Leptothorax nylanderi). Behavioral Ecology and Sociobiology 47:424-431.

Foitzik, S., M. Strätz, and J. Heinze. 2003. Ecology, life history and resource allocation in the ant, Leptothorax nylanderi. Journal of Evolutionary Biology 16:670-680.

$\rightarrow$ Fournier, D., S. Aron, and L. Keller. 2004. Significant reproductive skew in the facultatively polygynous ant Pheidole pallidula. Molecular Ecology 13:203-210.

$\rightarrow$ Frank, S. A. 1987. Variable sex ratio among colonies of ants. Behavioral Ecology and Sociobiology 20:195-201.

Gelman, A. 2006. Prior distributions for variance parameters in hierarchical models. Bayesian Analysis 1:515-534. 
of cicada-killer wasps (Sphecius speciosus Drury). Ecological Entomology 31:539-547.

$\rightarrow$ Gu, H., and S. Dorn. 2003. Mating system and sex allocation in the $\rightarrow$ gregarious parasitoid Cotesia glomerata. Animal Behaviour 66:259264.

Hadfield, J. D. 2010. MCMC methods for multi-response generalizec $\rightarrow$ linear mixed models: the MCMCglmm R package. Journal of Statistical Software 33:1-22.

$\rightarrow$ Hadfield, J. D., and S. Nakagawa. 2010. General quantitative genetic methods for comparative biology: phylogenies, taxonomies and multi-trait models for continuous and categorical characters. Journal of Evolutionary Biology 23:494-508.

$\rightarrow$ Hamilton, W. D. 1964. The genetical evolution of social behaviour. Journal of Theoretical Biology 7:1-52.

$\rightarrow$ Hammond, R. L., M. W. Bruford, and A. F. G. Bourke. 2006. A test of reproductive skew models in a field population of a multiplequeen ant. Behavioral Ecology and Sociobiology 61:265-275.

$\rightarrow$ Hannonen, M., and L. Sundström. 2003. Reproductive sharing among queens in the ant Formica fusca. Behavioral Ecology 14: 870-875.

$\rightarrow$ Hasegawa, E. 1994. Sex allocation in the ant Colobopis nipponicuc (Wheeler). I. Population sex ratio. Evolution 48:1121-1129.

$\rightarrow$ Helanterä, H., and F. L. W. Ratnieks. 2009. Sex allocation conflict in insect societies: who wins? Biology Letters 5:700-704.

$\rightarrow$ Helms, K. R. 1999. Colony sex ratios, conflict between queens and workers, and apparent queen control in the ant Pheidole desertorum. Evolution 53:1470-1478.

$\rightarrow$ Helms Cahan, S., and L. Keller. 2003. Complex hybrid origin of genetic caste determination in harvester ants. Nature 424:306-309.

$\rightarrow$ Herbers, J. M. 1979. The evolution of sex-ratio strategies in hyme nopteran societies. American Naturalist 114:818-834.

$\rightarrow-1990$. Reproductive investment and allocation ratios for the ant Leptothorax longispinosus: sorting out the variation. Americar Naturalist 136:178-208.

$\rightarrow$ Herbers, J. M., and V. S. Banschbach. 1998. Food supply and reproductive allocation in forest ants: repeated experiments give dif $\rightarrow$ ferent results. Oikos 83:145-151.

$\rightarrow-1999$. Plasticity of social organization in a forest ant species $\rightarrow$ Behavioral Ecology and Sociobiology 45:451-465.

$\rightarrow$ Herbers, J. M., and S. Grieco. 1994. Population structure of Leptothorax ambiguus, a facultatively polygynous and polydomous an $\rightarrow$ species. Journal of Evolutionary Biology 7:581-598.

$\rightarrow$ Hughes, W. O. H., B. P. Oldroyd, M. Beekman, and F. L. W. Ratnieks. 2008. Ancestral monogamy shows kin selection is key to the evo $\rightarrow$ lution of eusociality. Science 320:1213-1216.

$\rightarrow$ Iwanishi, S., S. Shin, and K. Ohkawara. 2007. Biasing mechanisms for the sex investment ratio in the monogynous and monandrou $\rightarrow$ ant Aphaenogaster smythiesi japonica Forel. Ethology Ecology and Evolution 19:275-289.

$\rightarrow$ Johnson, M. D. 1988. The relationship of provision weight to adult weight and sex ratio in the solitary bee, Ceratina calcarata. Ecological Entomology 13:165-170.

Keller, L. 1993. Queen number and sociality in insects. Oxford University Press, Oxford.

$\rightarrow$ Keller, L., and M. Genoud. 1997. Extraordinary lifespans in ants: a test of evolutionary theories of ageing. Nature 389:958-960.

$\rightarrow$ Kobayashi, A., and M. Shimada. 2000. Field sex ratio of a braconic $\rightarrow$ parasitoid wasp, Heterospilus prosopidis (Hymenoptera: Braconidae), in the southwestern United States: concordance with host $\rightarrow$ Re quality model. Annales of the Entomological Society of America 93:819-824.

Kümmerli, R., and L. Keller. 2007a. Extreme reproductive specialization within ant colonies: some queens produce males whereas others produce workers. Animal Behaviour 74:1535-1543.

. 2007b. Reproductive specialization among nestmate queens in the polygynous ant Formica exsecta. Behavioral Ecology 18:375383.

2008. Reproductive parameters vary with social and ecological factors in the polygynous ant Formica exsecta. Oikos 117: 580-590.

$\rightarrow-2009$. Patterns of split sex ratio in ants have multiple evolutionary causes based on different within-colony conflicts. Biology Letters 5:713-716.

Kümmerli, R., K. R. Helms, and L. Keller. 2005. Experimental manipulation of queen number affects colony sex ratio investment in the highly polygynous ant Formica exsecta. Proceedings of the Royal Society B: Biological Sciences 272:1789-1794.

Liautard, C., W. D. Brown, K. R. Helms, and L. Keller. 2003. Temporal and spatial variations of gyne production in the ant Formica exsecta. Oecologia (Berlin) 136:558-564.

Martins, R. P., Y. Antonini, F. A. da Silveira, and S. A. West. 1999. Seasonal variation in the sex allocation of a Neotropical solitary bee. Behavioral Ecology 10:401-408.

$\rightarrow$ Mehdiabadi, N. J., H. K. Reeve, and U. G. Mueller. 2003. Queens versus workers: sex-ratio conflict in eusocial Hymenopera. Trends in Ecology \& Evolution 18:88-93.

$\rightarrow$ Meunier, J., S. A. West, and M. Chapuisat. 2008. Split sex ratios in the social Hymenoptera: a meta-analysis. Behavioral Ecology 19: 382-390.

Morales, M. A., and E. R. Heithaus. 1998. Food from seed-dispersal mutualism shifts sex ratios in colonies of the ant Aphaenogasteer rudis. Ecology 79:734-739.

$\rightarrow$ Moreau, C. S., C. D. Bell, R. Vila, S. B. Archibald, and N. E. Pierce. 2006. Phylogeny of the ants: diversification in the age of angiosperms. Science 312:101-104.

Nonacs, P. 1986. Ant reproductive strategies and sex allocation theory. Quarterly Review of Biology 61:1-21.

Ode, P. J., and S. W. Rissing. 2002. Resource abundance and sex allocation by queen and workers in the harvester ant, Messor pergandei. Behavioral Ecology and Sociobiology 51:548-556.

Paini, D. R. 2004. Nesting biology of an Australian resin bee (Megachile sp.; Hymenoptera: Megachilidae): a study using trap nests. Australian Journal of Entomology 43:10-15.

Paini, D. R., and W. J. Bailey. 2002. Seasonal sex ratio and unbalanced investment sex ratio in the Banksia bee Hylaeus alcyoneus. Ecological Entomology 27:713-719.

Pamilo, P., and R. Rosengren. 1983. Sex ratio strategies in Formica ants. Oikos 40:24-35.

Pearson, B., A. F. Raybould, and R. T. Clarke. 1997. Temporal changes in the relationship between observed and expected sex-investment frequencies, social structure and intraspecific parasitism in Leptothorax tuberum (Formicidae). Biological Journal of the Linnean Society 61:515-536.

$\rightarrow$ Pedersen, J. S., and J. J. Boomsma. 1999. Effect of habitat saturation on the number and turnover of queens in the polygynous ant, Myrmica sulcinodis. Journal of Evolutionary Biology 12:903-917.

Queller, D. C., and J. E. Strassmann. 1998. Kin selection and social insects. BioScience 48:165-175.

Reuter, M., and L. Keller. 2001. Sex ratio conflict and worker pro- 


\section{The American Naturalist}

duction in eusocial Hymenoptera. American Naturalist 158:166- $\rightarrow$ Sundström, L., and F. L. W. Ratnieks. 1998. Sex ratio conflicts, mating 177.

frequency, and queen fitness in the ant Formica truncorum. Behavioral Ecology 9:116-121.

$\rightarrow$ Richards, M. H. 2001. Nesting biology and social organization of Halictus sexcinctus (Fabricius) in southern Greece. Canadian Jour $\rightarrow$ Sundström, L., M. Chapuisat, and L. Keller. 1996. Conditional manal of Zoology 79:2210-2220.

$\rightarrow$ Richards, M. H., and L. Packer. 1995. Annual variation in survival and reproduction of the primitively eusocial sweat bee Halictu $\rightarrow$ ligatus (Hymenoptera: Halictidae). Canadian Journal of Zoology 73:933-941. nipulation of sex ratios by ant workers: a test of kin selection theory. Science 274:993-995.

Teder, T., T. Tammaru, and R. Pedmanson. 1999. Patterns of host use in solitary parasitoids (Hymenoptera, Ichneumonidae): field evidence from a homogeneous habitat. Ecography 22:79-86.

$\rightarrow$ Rosenheim, J. A., P. Nonacs, and M. Mangel. 1996. Sex ratio anc $\rightarrow$ Trivers, R. L., and H. Hare. 1976. Haplodiploidy and the evolution multifaceted parental investment. American Naturalist 148:501-535.

$\rightarrow$ Ross, K. G. 1988. Differential reproduction in multiple-queen col $\rightarrow$ onies of the fire ant Solenopsis invicta (Hymenoptera: Formicidae). Behavioral Ecology and Sociobiology 23:341-355.

$\rightarrow$ Rosset, H., and M. Chapuisat. 2006. Sex allocation conflict in ants: when the queen rules. Current Biology 16:328-331.

$\rightarrow$ Rüppell, O., J. Heinze, and B. Holldobler. 2002. Intracolonial patterns of reproduction in the queen-size dimorphic ant Leptothorax ru $\rightarrow$ gatulus. Behavioral Ecology 13:239-247.

$\rightarrow$ Schwander, T., S. Helms Cahan, and L. Keller. 2007. Characterization and distribution of Pogonomyrmex harvester ant lineages with ge $\rightarrow$ netic caste determination. Molecular Ecology 16:367-387.

$\rightarrow$ Smith, C. R. 2007. Energy use and allocation in the Florida harvester ant, Pogonomyrmex badius: are stored seeds a buffer? Behaviora $\rightarrow$ Ecology and Sociobiology 61:1479-1487.

$\rightarrow$ Sorvari, J., and H. Hakkarainen. 2007. The role of food and colony size in sexual offspring production in a social insect: an experiment. Ecological Entomology 32:11-14.

$\rightarrow$ Soucy, S. L. 2002. Nesting biology and socially polymorphic behavior of the sweat bee Halictus rubicundus (Hymenoptera: Halictidae). Annales of Entomological Society of America 95:57-65.

$\rightarrow$ Sundström, L. 1995. Sex allocation and colony maintenance in monogyne and polygyne colonies of Formica truncorum (Hymenoptera: Formicidae): the impact of kinship and mating structure. American Naturalist 146:182-201.

Associate Editor: Blaine J. Cole Editor: Ruth G. Shaw

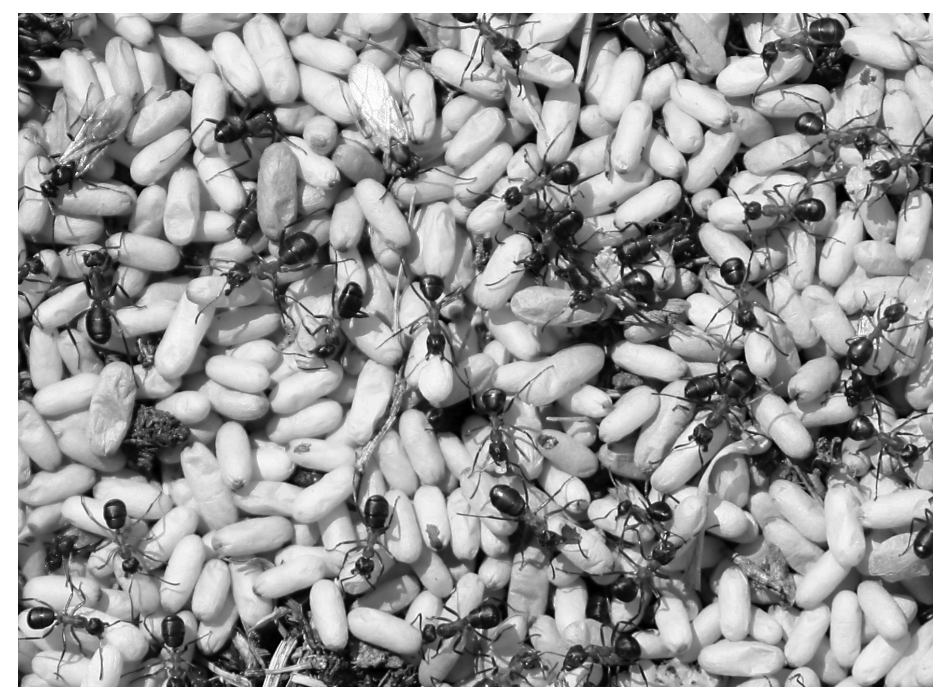

Brood rearing by workers of the ant Formica exsecta. Photograph by Rolf Kümmerli. 